\title{
Ultrasound Assessment of Bone Mass in Central Africans
}

\section{Population}

Joseph-Médard Kabeya-Kabenkama ${ }^{1}$, Jean Mukaya Tshibola ${ }^{1}$, Michel Lelo Tshikwela ${ }^{1}$, Tozin Rahma ${ }^{2}$, Jean-Jacques Malemba ${ }^{3}$, Rene Westhovens ${ }^{4}$, Jean-Marie Mbuyi-Mwamba ${ }^{3} \&$ Jan Dequeker $^{4}$

${ }^{1}$ Department of Radiology, Kinshasa University School of Medicine and Hospital, Democratic Republic of the Congo

${ }^{2}$ Department of Gynecology, Kinshasa University School of Medicine and Hospital, Democratic Republic of the Congo

${ }^{3}$ Department of Internal Medicine, Rheumatology, Kinshasa University School of Medicine and Hospital, Democratic Republic of the Congo

${ }^{4}$ Department of Rheumatology, U.Z Pellenberg, Leuven, Belgium

* Joseph-Médard Kabeya-Kabenkama, E-mail: jmdkabeya@gmail.com

Received: September 15, 2017 Accepted: September 26, 2017 Online Published: October 7, 2017 doi:10.22158/rhs.v2n4p323

URL: http://dx.doi.org/10.22158/rhs.v2n4p323

\begin{abstract}
Background: Osteodensitometry, a procedure increasingly accepted by clinicians to access osteoporosis is not yet fully validated by WHO. It requires the establishment of normal values and references curves for each population, and in our community, this is not yet assessed.

The purpose of this study was twofold: to describe the profile of the speed of sound of proximal phalangeal metaphysis and establish references curves in central Africans and to compare them with those of other populations specially Caucasians.

Methods: This cross sectional study was carried out at Kinshasa, Democratic Republic of the Congo in Central Africa from January to December 2016.

Four hundred twenty four subjects aged from 20 to 87 years old, were explored and the speed of sound in theirs proximal phalanges measured using ultrasound equipment. Age, gender, hormonal status and speed of sound were collected and analyzed.

Results: The mean value of the Amplitude Dependent Speed of Sound (AD-SoS) showed a growth feature with age (from $2056 \mathrm{~m} / \mathrm{sec}$ at second decade of life to $2145.27 \mathrm{~m} / \mathrm{sec}$ at fourth decade followed by a progressive decrease which was present in both sexes but more marked in postmenopausal women $(1927.06 \mathrm{~m} / \mathrm{sec})$. This mean value was higher than in Caucasian studies. In this study, age and hormonal status seems to be the bone quality most influencing anthropometric factors as seen in many series.
\end{abstract}


The curve profile with age was also a polynomial curve as seen in others populations of the world.

Conclusion: This study provides normal data for phalangeal ultrasound measurements and reference curve of central Africans which were compared to those of Western studies.

\section{Keywords}

bone, speed of sound, black Africans, quantitative ultrasound, osteoporosis

\section{Introduction}

Osteoporosis is a public health problem for both northern, over-equipped countries and for southern countries with limited access to heavy equipment (Lippuner et al., 2005; Maravic et al., 2005; WHO Study Group, 1994; Aspray et al.,1996; Kanis et al., 1997; Joly et al., 1999).

In some published studies, skeletal status was assessed using Dual-Energy X-Ray Absorptiometry (DXA) which is the gold standard method and the WHO validated one (Maravic et al., 2005; WHO Study Group, 1994). Instead of DXA, alternative methods for clinical assessment of bone status are proposed, and among them, the most used is Quantitative Ultrasound (QUS). The method does not rely on sources of ionizing radiation and is relatively less expensive and devices are portable.

The calcaneus is the most commonly measured site, but other skeletal sites such as phalanges, patella, tibia, or radius are also used (Kanis et al., 1997; Kaufman et al., 1993). In many studies, hand phalangeal measurements proved an ability to express qualitative features of bone tissue and architectural disorder related to osteoporosis (WHO Study Group, 1994; Aspray et al., 1996; Kanis et al., 1997; Kaufman et al., 1993).

Although the real significance of the measured parameters are still in study, ultrasonic methods have attracted increasing interest due to its advantages related above and seems to be an interesting tool for low-income countries (WHO Study Group, 1994; Hartl et al., 2002; Krieg et al., 2003; Vanderjagt et al., 2001; Gonçalves et al., 2015).

Phalangeal ultrasound Osteodensitometry is an increasingly accepted exploration by osteoporosis clinicians (Joly et al., 1999; Hartl et al., 2002; Krieg et al., 2003; Vanderjagt et al., 2001; Gonçalves et al., 2015), but it is not yet fully validated by WHO and most studies done to provide normative data for the QUS parameters, such as Amplitude Dependent Speed of Sound (AD-SoS), were based on European Caucasians samples.

There is a lack of research to support whether these references data may be applied to the central African black population. As it is reported that ethnicity and environmental habit may influences bone quality, those Caucasians references data may lead to contradictory results when used in non Caucasians as black populations of central Africa (WHO Study Group, 1994; Pluskiewicz et al., 1998; Aspray et al., 1996; Kaufman et al., 1993; Joly et al., 1999; Gonçalves et al., 2015; Ribeiro et al., 2010; Dib et al., 2005; Drozdzowska et al., 2003; Moayyeri et al., 2012).

Thus, this study aims to establish AD-SoS normative data by QUS of the phalanges in central African urban subjects, and to compare the result with those of Caucasians. 


\section{Subjects, Materials and Methods}

Four hundred twenty four consenting persons aged 20 to 87 years old recruited among relatives and workers of our institution, underwent phalangeal quantitative sonographic examination.

Prior to QUS measurements, all subjects were investigated by a physician to collect data concerning factors potentially influencing bone metabolism and to be included, one must meet conditionalities of lack of bone related pathologies.

No diseases or medications known to affect bone metabolism were noted in the group studied (prolonged diseases of the liver, kidney, thyroid gland, etc. or treatment using corticosteroids, anticonvulsants, thyroid hormones, etc.). No previous fractures occurred in the whole group.

Menopausal status and anthropometric parameters (age, height, and weight) were collected according to standardized procedures. Weight was measured $(\mathrm{kg})$ using portable digital scales to the nearest 0.1 $\mathrm{kg}$ and height was measured $(\mathrm{cm})$ using a vertical stadiometer to the nearest $0.1 \mathrm{~cm}$.

A DBM Sonic 1200 ultrasound machine (IGEA, Carpi, Italy) was used to calculate velocity. The unit consists of two probes mounted on an electronic caliper: one emitter (1.25 MHz pulses every 128 microseconds) and one receiver. The latter records the ultrasound energy after it has crossed the phalange (Figure 1). A standard ultrasound gel was used as acoustic coupling.

According to the method described by Cadossi et al. and reported by Joly et al., we determined the Ad-SoS $(\mathrm{m} / \mathrm{s})$ in the distal metaphyse of the proximal phalanges of the five finger of the left hand (non-dominant). Speed of sound in bone tissue was calculated considering the first signal with amplitude of at least $2 \mathrm{mV}$ at the receiving probe; thus, the measured speed of sound is amplitude dependent. A screen allows visualizations and the possibility of measurements of the acoustic impedance changes (Figure 1).
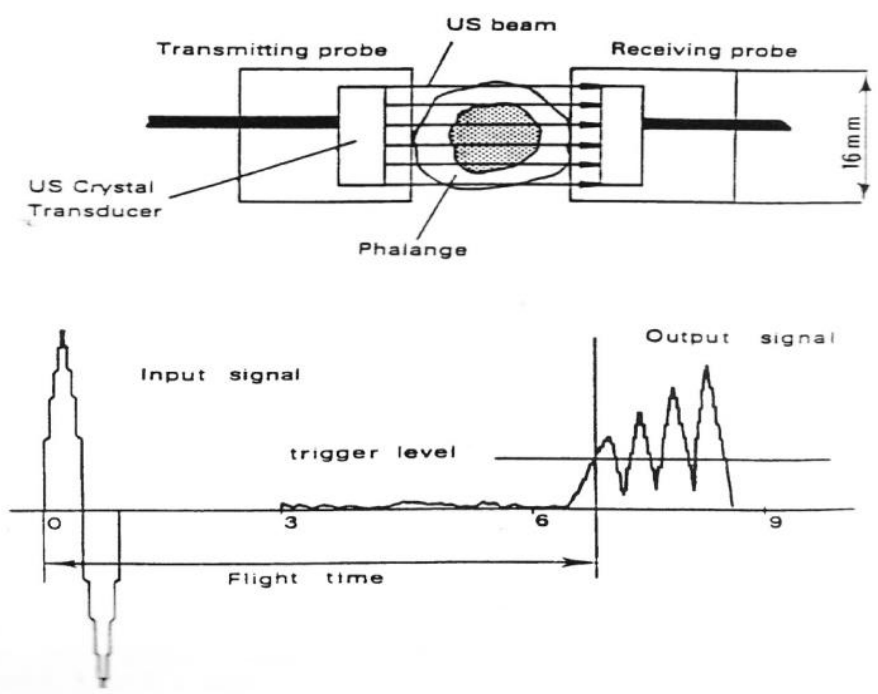

Figure 1. Schematic Representation of the Positioning of the Probes on the Phalanges (Top) and (Bottom) of the Waves Emitted and Generated on the Screen (Joly et al., 1999) 
For each subject, the amplitude-dependent speed of sound (AD-SoS) was measured 2 times by 2 different operators. The study design was approved by the local ethics committee, informed consent was obtained from each subject, and the study was conducted in accordance with the declaration of Helsinki for human studies.

\section{Statistical Analysis}

The coefficient of variation $(\mathrm{CV} \%=\mathrm{SD} /$ mean $\times 100 \%)$ was $0.95 \%$. and $1.34 \%$, and standardized $\mathrm{CV}$ (sCV $=\mathrm{CV} \% / 4 \mathrm{SD} / \mathrm{mean}$ ) was 3.42\%, both calculated according to the Glüer et al.'s (1995) proposition. The statistical analysis was performed using the Statistic program for Windows 5.1 (Tulsa, OK, USA, 1996) and SPSS 12.1.

All parameters analyzed in the study were normally distributed as determined by the Kolomogorov-Smirnoff test.

The differences in AD-SoS values between subgroups were analyzed using the Student's $t$-test. The pattern of age-related changes in AD-SoS was applied by different curve-fitting functions. Unpaired t tests and multiple stepwise regression analyses of AD-SoS with age, weight, and height were performed in order to evaluate the main factors influencing $\mathrm{AD}-\mathrm{SoS}$ values.

Linear regressions and multiple regressions were analyzed.

Mann-Whitney $U$ test was used to compare variables between sexes and no parametric multiple comparison test were performed when necessary.

The adjusted coefficient of determination $\left(r^{2}\right)$ was estimated. The results were expressed as mean, standard deviation (mean $\pm \mathrm{SD}$ ), range (minimum and maximum values) and absolute (n) and relative (\%) frequencies.

For all tests, statistical significance was established at $\mathrm{p}<0.05$.

\section{Results}

4.1 Evolution of Amplitude Dependent Speed of Sound (AD-SoS) at the Phalanges, Height and Weight with Age in Both Sexes

The age related variation of height, weight and values of AD-SoS on proximal phalanges of the left hand are given in Table 1. 
Table 1. Age Related Variation of Height, Weight and AD-SoS Values in Left Hand Proximal Phalanges

\begin{tabular}{lllllllllll}
\hline $\begin{array}{l}\text { AGE } \\
\text { (years })\end{array}$ & $\mathrm{N}$ & $\begin{array}{l}\text { HEIGHT } \\
(\mathrm{cm})\end{array}$ & $\begin{array}{l}\text { WEIGHT } \\
(\mathrm{kg})\end{array}$ & $\begin{array}{l}\text { SOS P1 } \\
(\mathrm{m} / \mathrm{s})\end{array}$ & $\begin{array}{l}\text { SOS P2 } \\
(\mathrm{m} / \mathrm{s})\end{array}$ & $\begin{array}{l}\text { SOS P3 } \\
(\mathrm{m} / \mathrm{s})\end{array}$ & $\begin{array}{l}\text { SOS P4 } \\
(\mathrm{m} / \mathrm{s})\end{array}$ & $\begin{array}{l}\text { SOS } \\
(\mathrm{m} / \mathrm{s})\end{array}$ & $\begin{array}{l}\text { P5 } \\
(\mathrm{m} / \mathrm{s})\end{array}$ \\
\hline $20-24$ & 59 & 155,67 & 55,55 & 2106,24 & 2156,72 & 2108,16 & 2120,01 & 2074,52 & 2107,73 \\
$25-29$ & 44 & 158,57 & 57,61 & 2111,38 & 2178,43 & 2118,19 & 2125,48 & 2060,33 & 2118,72 \\
$30-34$ & 44 & 161,64 & 55,76 & 2121,25 & 2211,75 & 2137,15 & 2147,81 & 2061,01 & 2135,79 \\
$35-39$ & 38 & 164,53 & 59,18 & 2106,68 & 2201,68 & 2133,99 & 2158,21 & 2125,79 & 2145,27 \\
$40-44$ & 44 & 165,15 & 65,2 & 2101,86 & 2159,14 & 2104,73 & 2114,04 & 2045,86 & 2105,12 \\
$45-49$ & 42 & 164,93 & 96,18 & 2083,57 & 2151,01 & 2096,14 & 2156,89 & 2052,71 & 2128,06 \\
$50-54$ & 39 & 170.7 & 67,33 & 2107,2 & 2156,36 & 2090,59 & 2097,05 & 2010,32 & 2092,30 \\
$55-59$ & 41 & 169,22 & 67,07 & 2053,24 & 2105,19 & 2057,89 & 2071,24 & 2002,24 & 2057,24 \\
$60-64$ & 37 & 167 & 67,58 & 2032,39 & 2088,17 & 2026,83 & 2031,22 & 1967,61 & 2029,24 \\
$65-87$ & 36 & 155,02 & 75 & 1990,72 & 2058,67 & 1983,53 & 1964,68 & 1927,06 & 1984,93 \\
\hline
\end{tabular}

Note. AD-SoS ranged from $2047 \mathrm{~m} / \mathrm{s}$ in the youngest (20 years old) to $1927.06 \pm 68 \mathrm{~m} / \mathrm{s}$ in the oldest one ( 87 years). The peak value is reached in fourth decade (35-39 years age group).

Figure 2 shows the evolution of the speed of sound (AD-SoS) and age in both sexes.

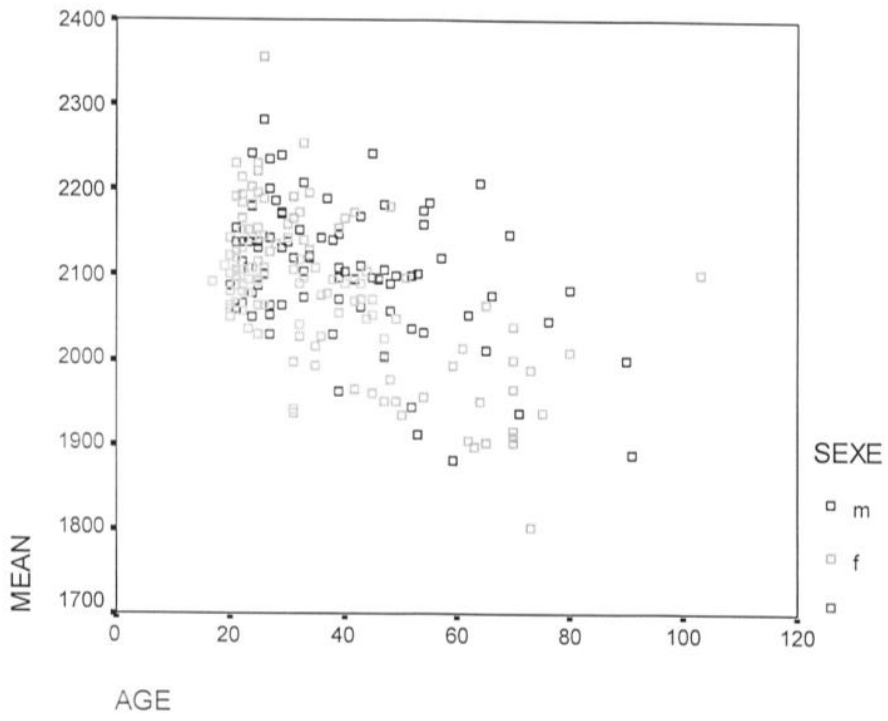

Figure 2. Evolution with Age of AD-SoS in Both Sexes

AD-SoS increased significantly between subgroups aged 20-24 years and 35-39 years $(\mathrm{p}<0.01)$ and the peak value (mean $2145.27 \mathrm{~m} / \mathrm{s}$ ) was achieved in 35-39 years old subjects.

Further, to the age of 50-54 years, a non-significant decrease was observed, and after the age of 54 year, 
a small, significant decrease in AD-SoS was noted.

From the peak value (34-39 years) to the value in the oldest (65-87 years), the mean AD-SoS dropped by $160.34 \mathrm{~m} / \mathrm{s}$, and a decrease per year was about $3.34 \mathrm{~m} / \mathrm{s}$.

4.2 Age Quartiles Related Evolution of AD-SoS and Correlations of Speed of Sound with Anthropobiometric Parameters

4.2.1 Age Quartiles and AD-SoS

Table 2 shows the evolution with age (divided into quartiles of age) of mean speed of sound (AD-SoS) and standard deviations at $95 \%$ significance in both sexes.

Table 2. Variations with Age of Mean AD-SOS and Standard Deviation

\begin{tabular}{lllll}
\hline Age group (years) & Sex & number & Mean AD-SoS $(\mathbf{m} / \mathbf{s})$ & S.d \\
\hline$<24$ & F & 32 & 2118,82 & 48,41 \\
$<24$ & M & 23 & 2114,29 & 52,79 \\
$24<32$ & F & 58 & 2116,70 & 86,39 \\
$24<32$ & M & 44 & 2137,04 & 65,12 \\
$32<47$ & F & 53 & 2078,07 & 70,82 \\
$32<47$ & M & 49 & 2115,35 & 60,22 \\
$\geq 47$ & F & 94 & 1976,80 & 81,00 \\
$\geq 47$ & M & 71 & 2060,57 & 91,65 \\
\hline
\end{tabular}

The dispersion of the values around the mean and its evolution in the quartiles of age is presented in Figure 3.

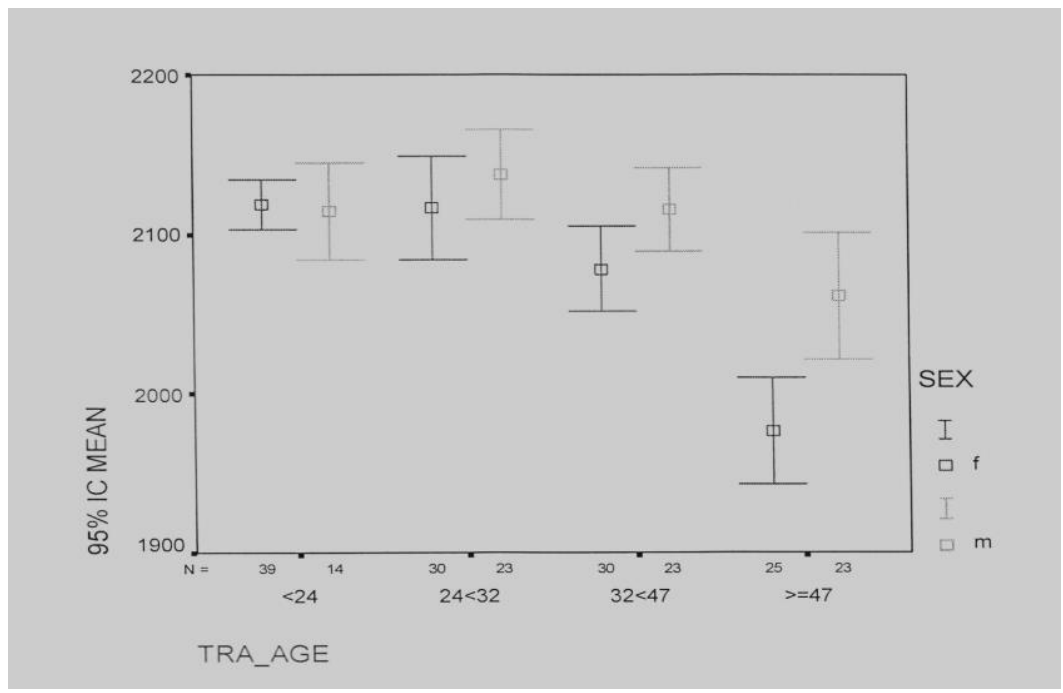

Figure 3. Dispersion of Values and Evolution of Speed of Sound (AD-SoS) with Age (Quartiles of Age) in Both Sexes 


\subsubsection{Regression Analysis}

Multiple stepwise regression analyses of AD-SoS with age were performed in both sex for the following age ranges: less than 24 years (increasing sos values in AD-SoS, $n=55$ ), 25 to 32 years (from the onset of the fast increase in AD-SoS to the peak value $n=102$ ), 33 to 47 years (peak value of AD-SoS $n=102$ ) and older than 47 years (after an achievement of peak value of AD-SoS to menopause and thereafter, $n=$ 165.

The following equations were obtained,

In female: $\mathrm{AD}-\mathrm{SoS}=-19.385 \mathrm{age}^{2}+78.64$ age +2055.6 with $\mathrm{r}^{2}=0,998$

In male: $\mathrm{AD}-\mathrm{SoS}=-24.787 \mathrm{age}^{2}+77.463$ age +2064.8 with $\mathrm{r}^{2}=0,9974$

The curves of cohesion are presented in Figure 4.

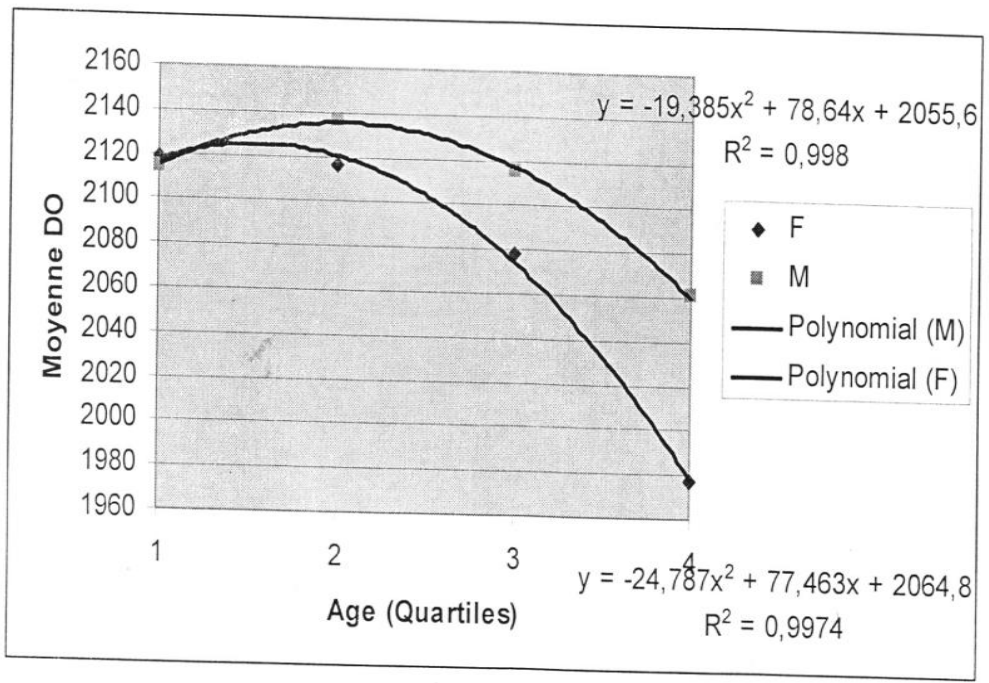

Figure 4. Quartiles of AD-SoS Curves of Cohesion

\subsubsection{Age Quartiles, AD-SoS, Height and Weight Linkage in Both Sexes}

Multiple stepwise regression analysis of AD-SoS with age, weight, and height was performed in the whole group and fisher's test values and probability are presented on Table 3.

Table 3. Probability Signification of Correlations (p) and Fisher Numbers (F)

\begin{tabular}{lllllllllll}
\hline Parameter & Age & Sex & Menop & Height & Weight & V.P1 & V.P2 & V.P3 & V.P4 & V.P5 \\
\hline AGE F & $*$ & 2.533 & 3.592 & 1.972 & 1.157 & 6.397 & 6.896 & 9.925 & 5.876 & 7.2 \\
AGE p & $*$ & 0.113 & 0.03 & 0.049 & 0.327 & 0.00001 & 0.00001 & 0.00001 & 0.00001 & 0.00001 \\
SEXE F & 2.533 & $*$ & 16.612 & 23.456 & 0.712 & 9.694 & 9.71 & 6.069 & 1.395 & 0.164 \\
SEXE p & 0.113 & $*$ & 0.00001 & 0.00001 & 0.4 & 0.002 & 0.002 & 0.015 & 0.239 & 0.686 \\
MENOP F & 3.652 & 16.612 & $*$ & 2.416 & 0.641 & 4.652 & 4.502 & 4.103 & 3.086 & 3.421 \\
MENOP p & 0.002 & 0.00001 & $*$ & 0.102 & 0.35 & 0.002 & 0.002 & 0.003 & 0.002 & 0.009 \\
\hline
\end{tabular}


Age has a very significant $(\mathrm{p}=0.00001)$ influence on Ad-SoS at all phalanges and AD-SoS was mainly dependent on age. The height are less significantly $(\mathrm{p}=0.049)$. AD-SoS is not correlated with weight or sex. The size (height) is correlated with sex $(\mathrm{p}=0,00001)$. Menopause is correlated with age and sex and is correlated with the speed of sound (AD-SoS) in the phalangeal metaphysis $(\mathrm{p}<0.002)$.

\section{Discussion}

The aim of this study was to determine the normal values of speed of sound and reference curves of amplitude-dependent speed of sound in central African population using an accessible and portable device and to compare them with those of Caucasians.

Skeletal status has been evaluated in several studies with the use of phalangeal QUS measurements (Joly et al., 1999; Hartl et al., 2002; Krieg et al., 2003; Vanderjagt et al., 2001; Gonçalves et al., 2015; Hodson et al., 2003; Drozdzowska et al., 2003; Ribeiro et al., 2010; Barkmann et al., 2002; Dib et al., 2005; Moayyeri et al., 2012; Wuster et al., 2000). However, the majority of them was done in Caucasians subjects and assessed usefulness of QUS at the hand phalanges to detect patients with osteoporosis.

Drozdzowska et al. studied a wide age range from early childhood to the elderly, reporting measurements in the right dominant hand. Wuster et al. studied the largest study reporting measurements in 10,115 females from several European countries.

To our knowledge, the current study is the first one performed in black central Africa urban subjects about normal and menopausal black subjects, reporting measurements on the non-dominant hand as done by Joly et al. in Belgian women.

This study seen low intra and inter observer coefficient of variation which traduce sensibility and reproducibility of QUS measurements and, furthermore, it's ability to detect changes in bone quality. Joly et al. found similar diagnostic sensitivity for the US measurements of the phalanges as for DXA of the lumbar spine and femoral neck when comparing the diagnostic sensitivity of bone mass obtained by QUS with the DBM SONIC 1200 on phallanges, as with ultrasound measurements of the calcaneus and with BMC and BMD obtained with DXA of spinal and proximal femur of the same individuals, and in osteoporotic patients and age-matched controls older than 50 years.

Our study found that the speed of sound (AD-SoS) increases with age up to 35-39 years where the peak values were reached and then decreases progressively with age with a steeper slope after 64 years. The AD-SoS values in the studies of Barkmann et al., Wuster et al. and Gonçalves et al. were generally lower than those obtained in the current study.

Studying younger subjects before peak of bone mass, Baroncelli et al. had an increase of $192 \mathrm{~m} / \mathrm{s}$, Barkmann et al. have of $176 \mathrm{~m} / \mathrm{s}$, and Gonçalves et al. obtained $191 \mathrm{~m} / \mathrm{s}$. Our study don't comprise younger subjects and the peak bone mass were found later than in German, Italian, Poland and Brazilians subjects.

The peak value of AD-SoS was reached at 35 to 39 years age group in our study.

Wuster et al. reported a peak value of AD-SoS close to peak value $(2116,70 \mathrm{~m} / \mathrm{s})$ in female of our study, 
achieved earlier in the age group 25 to 30 years.

Zamorano et al. reported a peak value of AD-SoS slightly higher $(2148 \mathrm{~m} / \mathrm{s})$ to ours (mean 2145,27 m/s) but reached also earlier (21 to 25 years).

After achievement of a peak Ad-SoS value, all studies observe a decrease of AD-SOS.

In urban African from peak to the age of 50-54 years, a non-significant decrease was observed, and thereafter the age a light significant decrease in AD-SoS was noted.

In this series, from the peak value to our oldest subject, AD-SoS dropped by $160,34 \mathrm{~m} / \mathrm{s}$, and the mean decrease per year was about $3.34 \mathrm{~m} / \mathrm{s}$.

Gonçalves et al. reported a decrease per year of $4.38 \mathrm{~m} / \mathrm{s}$. In other studies, decreases were smaller, and the drop in the study of Joly et al. was of $166 \mathrm{~m} / \mathrm{s}$ (mean: $3.32 \mathrm{~m} / \mathrm{s}$ ) from the third to eighth decade. It was $169 \mathrm{~m} / \mathrm{s}$ which is $3.38 \mathrm{~m} / \mathrm{s}$ annually in a study by Duboef F. et al. and the study by Zamorano et al. noted a drop of $184 \mathrm{~m} / \mathrm{s}(3.68 \mathrm{~m} / \mathrm{s}$ annually).

All of these comparisons show that the the AD-SoS is clearly higher in the urbans Africans (normal and menopaused population) than in other populations and the decrease rate is merely the same.

In the current study, the curve profile with age showed a polynomial curve. It was superimposable to those of other populations in the world (Aspray et al., 1996; Joly et al., 1999; Hartl et al., 2002; Krieg et al., 2003; Vanderjagt et al., 2001; Gonçalves et al., 2015) and influenced in the same order by the anthropo-biometric elements and the hormonal (menopausal) status. These result are similar to those of bone mass measured by radiogrammetry, bone mineral content and mineral density measured by DXA on other sites and several populations (WHO Study Group, 1994; Aspray et al., 1996; Gonçalves et al., 2015; Barkmann et al., 2002; Baroncelli et al., 2009; Dequeker et al., 1982).

Generally, age was the strongest factor influencing Ad-SoS values. And in our study: age, gender and menopausal status were the common influencing factor.

Besides considering weight, age and gender influences, bone mineral content also varies depend on race or skin color (WHO Study Group, 1994; Ribeiro et al., 2010).

But in Brazil, Gonçalves et al. and Ribeiro et al. did not found any influence of skin color on bone mass in theirs studies.

Vanderjagt et al. in Nigeria reported equivalent values in Caucasians and black and Aspray et al. reported that low-energy fractures remained rare in Gambian women even though the BMD at DXA was on average lower than that of the British woman.

Clinically significant fractures were not investigated in our series of blacks urban central Africa subjects, they were nor not reported in spite of the high number of postmenopausal women and the decrease in AD-SoS with age and hormonal status as already seen in Gambian women (Aspray et al., 1996). 


\section{Conclusions}

This study provides data for phalangeal ultrasound measurements in the normal black population of central Africa. Our reference curve shows differences with this of Caucasians, including higher $\mathrm{AD}-\mathrm{SoS}$ values, and peak value obtained at a later age, followed by an equivalent rate of decrease. An important finding derived from the study because less seriously affected skeletal status in the elderly, might suggest lower fracture risk in comparison to other female populations, highlighting the value of this publication.

Our results, like those of others studies suggest that quantitative ultrasound is a good alternative to DXA for bone mass and osteoporosis screening. We recommend similar studies on a larger scale and at different sites. Given its accessibility and price, the generalization of this measurement technique should be considered in Africa.

\section{Limitations}

The limitation of the study was that it is across-sectional design and relatively small number of subjects in the age groups. Among subjects studied, no fractures occurred; however, in some of them, clinically silent spine fractures might be present. Despite these limitations, this study carried out in Central Africa to access the sonographic profile of the speed of sound and references curves, seems to be the first one as far as we are aware.

It reports that the value the speed of sound was higher than in Caucasian studies. The curve profile was a polynomial curve as this of other population of the world. And age and hormonal status seems to be the most anthropometric factors influencing the quality of bone as seen in many series.

\section{Acknowledgements}

Authors are grateful to Dequeker Jan and Westhovens Rene of KU Leuven, Belgium for the DBM SONIC 1200 machine.

\section{References}

Aspray, T. J. et al. (1996). Low bone mineral content is common but osteoporotic fractures are rare in elderly rural Gambian women. J Bone Miner Res., 11, 1019-1025. https://doi.org/10.1002/jbmr.5650110720

Barkmann, R. et al. (2002). German pediatric reference data for quantitative transverse transmission ultrasound of finger phalanges. Osteoporos Int., 13, 55-61. https://doi.org/10.1007/s198-002-8338-8

Baroncelli, G. I. et al. (2009). Cross-sectional reference data for phalangeal quantitative ultrasound from early childhood to young-adulthood according to sex, age, skeletal growth, and pubertal development. Bone, 39, 159-173. https://doi.org/10.1016/j.bone.2005.12.010

Dequeker, J. et al. (1982). Radiogrammétrie osseuse. In A. M. Laval-Jeantet F. Caulin (Ed.), Mesure et 
signification du volume osseux et de la masse osseuse (pp. 19-23). Laboratoire Armour-Montagu, Paris.

Dib, L. et al. (2005). Impact of anthropometric, lifestyle, and body composition variables on ultrasound measurements in school children. Bone, 36, 736-742. https://doi.org/10.1016/j.bone.2005.01.009

Drozdzowska, B. et al. (2003). Skeletal status in males aged 7-80 years assessed by quantitative ultrasound at the hand phalanges. Osteoporos Int., 14, 295-300. https://doi.org/10.1007/s00198-002-1355-2

Drozdzowska, B. et al. (2005). Quantitative Ultrasound at the Hand Phalanges in 2850 Females Aged 7 to 77 years. A Cross-Sectional Study. Journal of Clinical Densitometry, 8(2), 216-221. https://doi.org/10.1385/JCD:8:2:216

Duboef, F. et al. (1996). Ultrasound velocity measured at proximal phalanges: Precision and age-related changes in normal females. Rev Rheum., 63, 427-434.

Fuerst, T. et al. (1995). Quantitative ultrasound. Eur $J$ Radiol., 20, 188-192. https://doi.org/10.1016/0720-048X(95)00650-F

Gluer, C. C. et al. (1995). Accurate assessment of precison errors: How to measure the reproducibilty of bone densitometry techniques. Osteoporos Int., 4, 262-270. https://doi.org/10.1007/BF01774016

Gonçalves, E. M. et al. (2015). Brazilian Pediatric Reference Data for Quantitative Ultrasound of Phalanges According to Gender, Age, Height and Weight. PLoS One, 10(6). https://doi.org/10.1371/journal.pone.0127294

Hartl, F. et al. (2002). Discriminatory ability of quantitative ultrasound parameters and bone mineral density in a population-based sample of post-menopausal women with vertebral fractures: Results of Basel osteoporosis study. J Bone Miner Res., 17, 321-330. https://doi.org/10.1359/jbmr.2002.17.2.321

Hodson, J. (2003). Quantitative ultrasound and risk factor enquiry as predictors of postmenopausal osteoporosis: Comparative study in primary care. BMJ, 326, 1250-1251. https://doi.org/10.1136/bmj.326.7401.1250

Joly, J. et al. (1999). Reference Curve and Diagnostic Sensitivity for a New Ultrasound Device for the Phalanges the DBM sonic 1200, in Belgian Women. Osteoporos Int., 9(4), 284-289. https://doi.org/10.1007/s001980050149

Kanis, J. A. et al. (1997). Guidelines for diagnosis and management of osteoporosis. The European Foundation for Osteoporosis and Bone Disease. Osteoporos Int., 7, 390-406. https://doi.org/10.1007/BF01623782

Kaufman, J. J. et al. (1993) Perspective: Ultrasound assessment of bone. J Bone Miner Res., 8, 517-525. https://doi.org/10.1002/jbmr.5650080502

Krieg, M. A. et al. (2003). Comparison of three bone ultrasounds for discrimination of subjects with and without osteoporotic fractures among 7562 elderly women. J Bone Miner Res., 18, 1261-1266. https://doi.org/10.1359/jbmr.2003.18.7.1261 
Lippuner, K. et al. (2005). Epidemiology and direct medical cost of osteoporotic fractures in men and women in Switzerland. Osteoporos Int., 16, S8-S17. https://doi.org/10.1007/s00198-004-1696-0

Maravic, M. et al. (2005). Incidence and cost of osteoporotic fractures in France during 2001. A methodological approach by the national hospital database. Osteoporos Int., 16, 1475-1480. https://doi.org/10.1007/s00198-011-1817-5

Moayyeri, A.et al. (2012). Quantitative ultrasound of the heel and fracture risk assessment: An updated meta-analysis. Osteoporos Int., 23, 143-153. https://doi.org/10.1007/s00198-011-1817-5

Pluskiewicz, W. et al. (1998). Ultrasound measurements of proximal phalanges in a normal Polish female population. Osteoporos Int., 8, 349-354. https://doi.org/10.1007/s001980050074

Ribeiro, R. R. et al. (2010). Comparison of bone quantity by ultrasound measurements of phalanges between white and black children living in Paraná, Brazil, with Europeans. Braz J Med Biol Res., 43, 976-981. https://doi.org/10.1590/S0100-879X2010007500089

Vanderjagt, D. J. et al. (2001). Assessment of the bone status of Nigerian women by ultrasound and biochemical markers. Calcif Tissue Int., 68, 277-284. https://doi.org/10.1007/BF02390834

World Health Organization. (1994). Assessment of fracture risk and its application to screening for postmenopausal osteoporosis. Report of WHO Study Group. World Health Organ Tech Rep Ser. $843,1-129$.

Wuster, C. et al. (2000). Phalangealosteosonogrammetry study: Age-related changes, diagnostic sensitivity, and discrimination power. $J$ Bone Miner Res., 15, 1603-1614. https://doi.org/10.1359/jbmr.2000.15.8.1603

Zamorano, J. D. P. et al. (2003). Reference curve of bone ultrasound measurements in proximal phalanges in normal Spanish women. $J$ Clin Densitom., 6, 373-380. https://doi.org/10.1385/JCD:6:4:373 